\title{
Muuttaako uudelleenryhmittely hiehojen sosiaalista käyttäytymistä?
}

\author{
Satu Raussi ${ }^{1,2)}$, Alain Boissy ${ }^{3)}$, Eric Delval ${ }^{3)}$, Philippe Pradel $^{4)}$, Jutta Kaihilahti ${ }^{5)}$ ja Isabelle Veissier ${ }^{3)}$ \\ ${ }^{1)}$ MTT Maa ja elintarviketalouden tutkimuskeskus, maatalousteknologian tutkimus (Vakola), \\ Vakolantie 55, 03400 Vihti \\ ${ }^{2)}$ Eläinten hyvinvoinnin tutkimuskeskus, Helsingin yliopisto, Eläinlääketieteellinen tiedekunta, PL 57, \\ 00014 Helsingin yliopisto \\ ${ }^{3)}$ INRA, Centre de Clermont-Ferrand/Theix, URH-ACS, 63122 Saint-Genès-Champanelle, France \\ 4) INRA, Centre de Clermont-Ferrand/Theix, Domaine de Marcenat, 15190 Marcenat, France \\ ${ }^{5)}$ Estonian Agricultural University, Institute of Animal Science/Department of Animal Housing \\ Technology, 51014 Tartu, Estonia
}

\section{Johdanto}

Lehmät, hiehot ja vasikat muodostavat luonnossa ryhmiä, joihin harvoin otetaan uusia jäseniä (Bouissou ym., 2001). Vakaissa sosiaalisissa ryhmissä kasvattamisen onkin ajateltu olevan nautojen hyvinvoinnin kannalta edullista. Tuotanto-olosuhteissa lypsylehmien lehmävasikat vieroitetaan emistään heti tai muutaman päivän kuluttua syntymästä, ja kasvatetaan ryhmässä toisten lehmävasikoiden kanssa. Hiehoja pidetään tiloilla yleensä hiehoryhmissä, ja ryhmittely lehmien joukkoon tapahtuu joko ennen poikimista tai heti sen jälkeen. Hiehoilla myös käydään kauppaa tilojen välillä. Tuotanto-oloissa vasikoiden ja hiehojen sosiaalinen ympäristö voi siis muuttua useasti.

Nautojen sosiaaliseen käyttäytymiseen vaikuttavat sosiaalinen kokemus, ikä ja sukukypsyys. Hierarkiasuhteiden selvittely on nopeampaa ja aggressiiviset yhteenotot vähäisempiä niillä hiehoilla ja vasikoilla, joilla on aikaisempaa kokemusta uudelleenryhmittelystä, verrattuna hiehoihin ja vasikoihin joilla ryhmittelykokemusta ei ole (Bouissou, 1975; Veissier ym., 1994). Toisaalta monta kerta ryhmiteltyjen vasikoiden sosiaalinen asema on huonompi, kuin vain yhden kerran ryhmiteltyjen (Veissier ym., 1994).

Vasikoilla on ensimmäisten elinkuukausien aikana hyvin vähän aggressiivisia yhteenottoja ja nekin ovat leikinomaisia, sosiaalinen hierarkia ei myöskään ole pienillä vasikoilla kunnolla kehittynyt (Bouissou, 1977; Canali ym., 1986; Reinhardt ja Reinhardt, 1982). Tehokkaita aggressiivisia yhteenottoja ilmenee hiehoilla sukukypsyyden saavuttamisen aikoihin, jolloin todellinen dominanssihierarkia alkaa muodostua (Bouissou, 1977). Dominanssihierarkia auttaa vähentämään ryhmän sisäisiä konflikteja (Bouissou ja Signoret, 1970). Nautaryhmän sosiaaliseen käyttäytymiseen liittyy paljon muutakin kuin dominanssihierarkia. Ryhmän sosiaalinen käyttäytyminen muodostuu ryhmän jokaisen yksilön persoonasta ja yksilöiden sosiaalisesta vetovoimasta, kuten jo vasikasta toisensa tunteneiden nautojen pitkäaikaisista kaverisuhteista (Arnold, 1985; Ewbank, 1967). Pitkäaikaiset kaverit suosivat toisiaan; ne makaavat ja syövät mieluiten toistensa lähellä (Bouissou ja Andrieu, 1978; Bouissou ja Hövels, 1976).

Tämän tutkimuksen tarkoitus oli selvittää muuttaako toistuva uudelleenryhmittely hiehojen sosiaalista käyttäytymistä. Kysyimme myös, tottuvatko hiehot toistuvaan ryhmittelyyn reagoimalla vähemmän jokaisen ryhmittelyn jälkeen, ja oppivatko ne kokemuksen myötä muodostamaan dominanssihierarkian nopeasti ja mahdollisimman vähäisellä aggressiivisella käyttäytymisellä.

\section{Aineisto ja menetelmät}

Koe toteutettiin Ranskan Auvergnessa INRA:n Marcenatin tutkimusasemalla. Kokeeseen otettiin 32 Holstein lehmävasikkaa, jotka olivat peräisin kahdelta INRA:n tutkimustilalta. Vasikat kasvatettiin pareittain heti syntymän jälkeen ja samat parit siirrettiin puolen vuoden ikäisinä $4 \mathrm{~m}$ x $5 \mathrm{~m}$ kokoisiin olkikuivitettuihin parikarsinoihin. Eläimillä oli koko ajan vapaasti tarjolla vettä ja kuivaa heinää ja ne saivat kaksi kertaa päivässä täysrehuannokset. Eläinten terveys tarkistettiin kaksi kertaa päivässä ja samalla lisättiin tarvittaessa karsinoihin kuivikkeita.

Kahdeksan kuukauden iässä eläinten plasman progesteronipitoisuudet määritettiin. Täten varmistettiin, että jokainen eläin oli saavuttanut puberteetin ennekuin koekäsittelyt alkoivat. Koekäsittelyt aloitettiin, kun hiehot olivat 11 kuukauden ikäisiä. Pareittain kasvatetuista 32:sta hiehosta 16 ryhmiteltiin vieraaseen karsinaan ennestään tuntemattoman parin kanssa 16 kertaa kahden kuukauden aikana (koekäsittely: uudelleenryhmittely). Kontrollihiehot, 16 eläintä, pysyivät koko kokeen ajan saman parin kanssa samassa karsinassa (koekäsittely: kontrolli). Kaikki hiehot punnittiin ennen jokaista uudelleenryhmittelyä. 
Uudelleenryhmittelyn vaikutuksia hiehojen sosiaaliseen käyttäytymiseen tutkittiin tarkkailemalla hiehojen käyttäytymistä kotikarsinassa: kolme tuntia uudelleenryhmittelyjen 2, 7,13 ja 16 jälkeen ja 24 tuntia ennen uudelleenryhmittelyjä sekä niiden välillä. Sosiaalisessa testissä, ennen viimeistä uudelleenryhmittelyä, tutkittiin hiehojen käyttäytymistä vieraan, toisesta käsittelystä tulevan hiehon kanssa testikentällä.

Käyttäytyminen kolme tuntia uudelleenryhmittelyn jälkeen Hiehojen käyttäytymistä tarkkailtiin kolmen tunnin ajan välittömästi toisen, seitsemännen, kolmannentoista ja viimeisen eli kuudennentoista uudelleenryhmittelyn jälkeen. Hiehot otettiin ulos kotikarsinastaan yksitellen punnittavaksi ja heti punnituksen jälkeen uudelleenryhmiteltävä hieho laitettiin uuteen karsinaan. Kontrollihiehot palautettiin punnituksen jälkeen lähtökarsinaansa. Käyttäytymistarkkailu alkoi heti kun molemmat hiehot olivat punnituksen jälkeen karsinassa ja kesti kolme tuntia. Hiehojen käyttäytyminen kuvattiin ja nauhoitettiin. Nauhat purettiin myöhemmin käyttäen apuna Observer Video Pro ohjelmaa (Noldus, Alankomaat). Tarkkailumenetelmä oli jatkuva tarkkailu, eli kaikki ennalta päätetyt käyttäytymispiirteet rekisteröitiin yksilöllisesti. Rekisteröidyt, mahdolliset pitkäkestoiset, käyttäytymistilat olivat seuraavat: makaaminen, seisominen tekemättä mitään muuta, syöminen, taistelu parin kanssa (molemmat työntävät toisiaan aggressiivisesti), leikkiminen päällä toista hangaten, toisen nuoleminen muualta kuin hävyn alueelta ja toisen nuoleminen hävyn alueelta. Rekisteröidyt nopeat käyttäytymistapahtumat olivat seuraavat: tehokas uhkaus (uhattu väistyy), tehoton uhkaus (uhattu ei väisty), tehokas pusku (aggressiivinen pusku päällä tai sarvella toisen kehoon), tehoton pusku, pakeneminen (pään kääntäminen tai karkuun lähteminen kun toinen lähestyy), päät vastakkain seisominen (kumpikaan ei työnnä toista), päät vastakkain hankaaminen, päällä nojaaminen vasten toisen kehoa, pienet puskut (usein toistuva, ei aggressiivinen), vartalo vasten vartaloa työntäminen, leuan pitäminen toisen selän päällä, astumiskäyttäytyminen eli hyppy toisen selkään, flechmen-reaktio (ylähuulen rullaaminen) ja karsinarakenteiden nuoleminen. Rekisteröidyt käyttäytymistilat ja tapahtumat olivat toisensa pois sulkevia. Jälkeenpäin kaikki aggressiivinen käyttäytyminen, tehokas aggressiivinen käyttäytyminen, tehoton aggressiivinen käyttäytyminen, ei-aggressiivinen käyttäytyminen ja seksuaalinen käyttäytyminen laskettiin yhteen. Käyttäytymisestä raportoitiin käyttäytymispiirteen frekvenssi, kesto sekä se, kuinka paljon aikaa vei ennen kuin tietty käyttäytymispiirre ensimmäistä kertaa havaittiin eli käyttäytymisen viive (latenssi).

Vuorokauden käyttäytyminen Hiehojen vuorokautista ajankäyttöä tarkkailtiin, jotta nähtäisiin toistuvan uudelleenryhmittelyn mahdolliset pitempiaikaiset vaikutukset eläinten peruskäyttäytymiseen. Käyttäytymistä seurattiin ennen ensimmäistä uudelleenryhmittelyä sekä viidennen, kahdennentoista ja viimeisen eli kuudennentoista uudelleenryhmittelyn jälkeen. Käyttäytyminen kuvattiin ja nauhoitettiin sekä myöhemmin purettiin nauhalta kirjaten taulukkolaskentaohjelmaan jokaisen hiehon käyttäytyminen viiden minuutin välein. Tarkkailtavat käyttäytymisluokat olivat aktiivisuus ja etäisyys. Aktiivisuusluokassa rekisteröitiin seuraavia käyttäytymispiirteitä: makaaminen, seisominen, liikkuminen, syöminen ja juominen. Etäisyysluokassa rekisteröidyt käyttäytymispiirteet olivat: hiehot kosketuksissa keskenään, hiehojen välinen etäisyys yhtä suuri tai pienempi kuin yksi metri tai hiehojen välinen etäisyys suurempi kuin yksi metri. Eri aktiivisuus- ja etäisyysluokat olivat toisensa pois sulkevia. Aktiivisuus- ja etäisyysluokista raportoitiin niiden frekvenssi, aktiivisuus- ja etäisyysluokan muutosten lukumäärä sekä aktiivisuus- ja etäisyysluokan jaksojen määrä.

Avokenttätesti vieraan hiehon kanssa Testikentälle tuotiin yksi uudelleenryhmittely- ja yksi kontrolliryhmän hieho. Hiehot olivat kentällä testissä 8 minuutin ajan. Tarkoituksenamme oli selvittää käsittelyryhmien välisiä eroja kun eläimet kohtaavat vieraan lajitoverin karsinan ulkopuolisessa ympäristössä, sillä oletuksena oli, että uudelleenryhmitellyillä hiehoilla olisi enemmän sosiaalista kokemusta ja ne olisivat aggressiivisempia ja hallitsevampia kuin kontrollihiehot. Testi tarkkailtiin suoraan ja koodattiin kuten käyttäytymishavainnot kolme tuntia uudelleenryhmittelyn jälkeen.

\section{Tulokset}

Käyttäytyminen kolme tuntia uudelleenryhmittelyn jälkeen Uudelleenryhmitellyt hiehot seisoivat enemmän toisen ja seitsemännen ryhmittelyn jälkeen $(\mathrm{P}<0,05)$ ja makasivat vähemmän jokaisen ryhmittelyn jälkeen $(P<0,05)$ verrattuna kontrollihiehoihin. Uudelleenryhmitellyt hiehot nuuskivat ja nuolivat karsinaa enemmän jokaisen uudelleenryhmittelyn jälkeen $(\mathrm{P}<0,05)$ verrattuna kontrollihiehoihin. Uudelleenryhmitellyt hiehot olivat aggressiivisia jokaisen uudelleenryhmittelyn jälkeen, kontrollihiehoilla aggressiivista käyttäytymistä vastaavana ajankohtana oli hyvin vähän (Taulukko 1). Vähiten aggressiivista käyttäytymistä havaittiin seitsemännen uudelleenryhmittelyn jälkeen kun taas viimeisen uudelleenryhmittelyn jälkeen aggressiivista käyttäytymistä oli eniten. Sosiaalisen hierarkian 
muodostuminen uudelleenryhmitellyillä hiehoilla oli nopeinta seitsemännen uudelleenryhmittelyn jälkeen ja hitainta viimeisen eli 16. uudelleenryhmittelyn jälkeen (Taulukko 1).

Taulukko 1. Hiehojen aggressiivinen käyttäytyminen (käsittelyryhmän keskiarvo \pm SE) ja uudelleenryhmiteltyjen hiehojen hierarkian muodostumiseen kulunut aika (uudelleenryhmiteltyjen keskiarvo \pm SE) kolme tuntia ryhmittelyjen $2,7,13$ ja 16 jälkeen.

\begin{tabular}{|l|l|l|l|l|l|l|l|l|}
\hline & \multicolumn{2}{|l|}{ Ryhmittely 2 } & \multicolumn{2}{l|}{ Ryhmittely 7 } & \multicolumn{2}{l|}{ Ryhmittely 13 } & \multicolumn{2}{l|}{ Ryhmittely 16 } \\
\cline { 2 - 8 } & Kontrolli & Ryhmittely & Kontrolli & Ryhmittely & Kontrolli & Ryhmittely & Kontrolli & Ryhmittely \\
\hline $\begin{array}{l}\text { Aggressiiviset } \\
\text { yhteenotot, } \\
\text { kertaa }\end{array}$ & $0,3 \pm 0,2$ & $18,5 \pm 4,1$ & $0,1 \pm 0,1$ & $13,6 \pm 2,4$ & $0,6 \pm 0,2$ & $23,8 \pm 4,2$ & $1,3 \pm 0,6$ & $32,6 \pm 6,3$ \\
\hline $\begin{array}{l}\text { Hierarkian } \\
\text { muodostumiseen } \\
\text { kulunut aika, } \\
\text { minuuttia }\end{array}$ & $134 \pm 17$ & & $84 \pm 20$ & & $121 \pm 22$ & & $158 \pm 56$ \\
\hline
\end{tabular}

Vuorokauden käyttäytyminen Ennen ensimmäistä ryhmittelyä kontrolli- ja uudelleenryhmiteltyjen hiehojen käyttäytymisessä ei havaittu eroja. Viidennen ryhmittelyn jälkeen kontrollihiehoilla oli keskenään useammin sosiaalista kanssakäymistä kuin uudelleenryhmitellyillä $(\mathrm{P}=0,06)$, kontaktijaksot myös kestivät kontrollihiehoilla pitempään $(P=0,05)$. Kahdennentoista ryhmittelyn jälkeen uudelleenryhmitellyt hiehot olivat useammin kauempana, yli metrin päässä, toisistaan verrattuna kontrollihiehoihin $(P=0,06)$. Viimeisen ryhmittelyn jälkeen uudelleenryhmitellyt hiehot liikkuivat enemmän, niiden käyttäytymisjaksot olivat lyhyempiä ja ne vaihtoivat tekemistä useammin päivän mittaan verrattuna kontrollihiehoihin ( $\mathrm{P}<0,05$ kaikissa tapauksissa).

Avokenttätesti vieraan hiehon kanssa Uudelleenryhmiteltyjen ja kontrollihiehojen käyttäytymisessä ei havaittu eroja avokenttätesteissä, joissa yksi kontrollihieho ja yksi uudelleenryhmitelty hieho laitettiin kentälle kahdeksan minuutin testiajaksi. Kontrollihiehoilla aggressiivista käyttäytymistä havaittiin keskimäärin 11,9 kertaa kahdeksan minuutin testin aikana ja vastaava luku ryhmitellyillä hiehoilla oli 11,4 kertaa.

\section{Tulosten tarkastelu}

Hiehot eivät tottuneet toistuvaan uudelleenryhmittelyyn toisin kuin vasikat Veissierin ym. (2001) kokeessa. Hiehot reagoivat jokaiseen uudelleenryhmittelyyn aggressiivisella käyttäytymisellä. Tämä voi johtua siitä, että hiehot, toisin kuin vasikat, olivat sukukypsiä. Puberteetissa tehokas aggressiivinen käyttäytyminen lisääntyy ja sitä tarvitaan, sillä varsinainen dominanssihierarkia alkaa tuolloin muodostua. Vähiten aggressiivisuutta havaittiin seitsemännen ryhmittelyn jälkeen ja eniten viimeisen eli 16:sta ryhmittelyn jälkeen. Hierarkian muodostus oli nopeinta seitsemännen ja hitainta 16:sta ryhmittelyn jälkeen.

Vuorokauden käyttäytymistarkkailussa uudelleenryhmiteltyjen hiehojen todettiin pitävän toisiinsa enemmän etäisyyttä kuin kontrollihiehojen, tämä havaittiin ryhmittelyjen $5-6$ ja $12-13$ välisenä aikana. Pitkäaikaisten nautakavereiden tiedetään viihtyvän toistensa läheisyydessä (Bouissou ja Hövels, 1976; Bouissou ja Andrieu, 1978). On siten luonnollista, että uudelleenryhmitellyt hiehot, jotka tunsivat toisensa vasta muutaman päivän ajalta, pitivät toisiinsa enemmän etäisyyttä, kuin kontrollihiehot, jotka tunsivat karsinatoverinsa jo varhaisesta vasikkavaiheesta saakka.

Nautatovereilla tiedetään olevan rauhoittava vaikutus toisiinsa (Boissy ja Le Neindre, 1990; Takeda ym., 2003). Vuorokauden käyttäytymistarkkailussa tällaista vaikutusta ei havaittu uudelleenryhmitellyillä hiehoilla 16 ryhmittelyn jälkeen; ne olivat tuolloin kontrollihiehoja aktiivisempia. Näyttää siltä, että lyhyen aikaa kestäneellä karsinatoveruudella rauhoittavaa vaikutusta ei ole.

Testikentällä tehdyn sosiaalisen testin tulosten perusteella toistuvalla uudelleenryhmittelyllä ei näyttäisi olevan pitkäaikaisia vaikutuksia hiehojen sosiaaliseen käyttäytymiseen.

\section{Johtopäätökset}

Uudelleenryhmittely aiheutti aina akuutin reaktion, mutta suuria pitkäaikaisia käyttäytymisvaikutuksia sillä ei näyttänyt olevan. Vuorokauden käyttäytymistarkkailuissa erot eivät olleet suuria, eikä kontrolli- ja uudelleenryhmiteltyjen hiehojen käyttäytymisessä ollut lainkaan eroja avokenttätestissä vieraan hiehon kanssa. Hiehoille optimaalinen määrä uudelleenryhmittelyjä olisi tämän kokeen tulosten perus- 
teella noin seitsemän. Tuollainen määrä sosiaalista kokemusta vähensi aggressiivisen käyttäytymisen määrää ja auttoi muodostamaan hierarkian mahdollisimman nopeasti.

Tämän tutkimuksen tulosten perusteella, hiehoja olisi hyvä ryhmitellä muutamia kertoja tuntemattomien hiehojen kanssa ennen niiden laittamista lehmien joukkoon, jotta ne saisivat tarpeellista sosiaalista kokemusta hierarkian muodostamisesta.

\section{Kirjallisuus}

Arnold, G.W. 1985. Associations and Social Behaviour. Julkaisussa: Ethology of Farm Animals. Elsevier Scientific Publishing Company, Amsterdam, sivut 233-248. Toim. A.F. Fraser.

Boissy, A. \& Le Neindre, P. 1990. Social Influences on the Reactivity of Heifers: Implications for Learning Abilities in Operant Conditioning. Appl. Anim. Behav. Sci. 25: 149-165.

Bouissou, M.F. 1975. Etablissement des relations de dominance-soumission chez les bovines domestiques. III. Effet de l'expérience sociale. Z. Tierpsychol. 38: 419-435.

Bouissou, M.F. 1977. Etude du développement des relations de dominance-subordination chez les bovines, à l'aide d'épreuves de competition alimentaire. Biology of Behaviour 2: 213-221.

Bouissou, M.F. \& Andrieu, S. 1978. Etablissement des relations preferentielles chez les bovins domestiques. Behaviour 64: 148-157.

Bouissou, M.F. \& Hövels, J. 1976. Effet d'un contact précoce sur quelques aspects du comportement social des bovines domestiques. Biology of Behaviour 1: 17-36.

Bouissou, M. F. \& Signoret, J. P. 1970. La hiérarchie sociale chez les mammifères. Rev. Comp. Animal 4: 4361.

Bouissou, M.F., Boissy, A., Le Neindre, P. \& Veissier, I. 2001. The Social Behaviour of Cattle. Toim. L.J. Keeling \& H.W. Gonyoy. Social Behaviour of Farm Animals. CABI International, Wallingford, sivut 113-145.

Canali, E., Verga, M., Montagna, M. \& Baldi, A. 1986. Social interactions and induced behavioural reactions in milk-fed female calves. Applied Animal Behaviour Science 16: 207-215.

Ewbank, R. 1967. Behaviour of Twin Cattle. Journal of Dairy Science 50: 1510-1512.

Reinhardt, V. \& Reinhardt, A. 1982. Social behaviour and social bonds between juvenile and sub-adult Bos indicus calves. Applied Animal Ethology 9: 92-93.

Takeda, K., Sato, S. \& Sugawara, K. 2003. Familiarity and group size affect emotional stress in Japanese Black heifers. Appl. Anim. Behav. Sci. 82: 1-11.

Veissier, I., Gesmier, V., Le Neindre, P., Gautier, J.Y. \& Bertrand, G. 1994. The effects of rearing in individual crates on subsequent social behaviour of veal calves. Applied Animal Behaviour Science 41: 199-210.

Veissier, I., Boissy, A., de Passille, A.M., Rushen, J., van Reenen, C.G., Roussel, S., Andanson \& S., Pradel, P. 2001. Calves' responses to repeated social regrouping and relocation. Journal of Animal Science 79: 2580-2593. 